\title{
A MACROECONOMIC MODEL FOR SOUTH AFRICA: A NON-LINEAR ECONOMETRIC MODELLING APPROACH
}

\author{
Marinda Pretorius \\ University of Johannesburg \\ marindap@uj.ac.za \\ Ilse Botha \\ University of Johannesburg
}

February 2007

\begin{abstract}
Econometric models are often made up of assumptions that never truly match reality. One of the most challenged requirements is that the coefficients of econometric models remain constant over time, in the sense that it is assumed that the future will be similar to the past. If the assumption of constant coefficients is not satisfied, any conclusions reached from normal (constant coefficient) models will be biased. Another, very closely related, contested assumption is that the functional form (usually linear) of a model remains unchanged over time. The theory of linearity has long been the centre of all econometric model-building. According to Teräsvirta (1994), if linear estimates were not successful in practice, they would have been forsaken long ago, and this has certainly not been the case. Quite the opposite has been experienced: some very influential ideas based on the linear relationships between variables, like cointegration analysis, have been established. Nonetheless, there are definite situations in which linear models are unable to grasp the underlying economic theory of the data accurately. This article addresses the problem of non-linearity by applying smooth transition autoregressive (STAR) specifications to an existing simultaneous macroeconomic model of the South African economy. The results support the view that non-linear models provide better forecasts than linear specifications of equations.
\end{abstract}

Keywords:

Non-linearity, emerging market, STAR, constant coefficients, linear specifications. 


\section{INTRODUCTION}

Econometric models are often made up of assumptions that never truly match reality. One of the most challenged assumptions is that the functional form (usually linear) of a macroeconomic model stays the same over time, in the sense that it is assumed that the future will be similar to the past. If the assumption of linearity is not satisfied, any conclusions obtained from normal (linear) models will be biased.

The theory of linearity has long been the centre of all econometric model-building. According to Teräsvirta (1994), if linear estimates were not successful in practice they would have been forsaken long ago, and this has certainly not been the case. Quite the opposite has been experienced: some very influential ideas have been established upon the linear relationships between variables, like cointegration analysis. Nonetheless, there are definite situations in which linear models are unable to grasp the underlying economic theory of the data accurately.

In developing economies such as South Africa's, the notion of linearity is very far-fetched because these economies are frequently characterized by changes in economic policy as well as economic structure. The Croatian economy, for example, went through extensive changes in economic policies and structure and according to Erjavec (2003) it is crucial that standard econometric techniques need to be adapted for these economies in transition. It is thus important to see these changes in developing economies as valuable information for econometric modelling. Incorporating these changes into models will provide not only better forecasts but also better information for policy analyses as well. Jerome (2004) also stresses that it is important for macroeconomic modelling teams to include all relevant information and insights in econometric models to keep them accurate and relevant.

Recent research has focused on the econometric modelling of possible structural changes (time-varying coefficients) and changes in the functional form of models over time (nonlinear methods). The aim of this article is to compare the forecasts of a pure linear specification to those of a combination of linear and non-linear specifications of a macroeconomic model of the South African economy.

\section{METHODOLOGY}

\subsection{Linear model}

The pure linear specification was applied to a current macroeconomic model of the South African economy by using the popular ordinary least squares (OLS) method. It was decided that the OLS macroeconomic model would be used as benchmark seeing that it remains the device used to begin almost all empirical research (Greene 2003).

The model consisted of 53 simultaneous equations. The data period for most macroeconomic models for the South African economy usually runs from 1980. In this article the sample period was from 1990 quarter 1 to 2004 quarter 3, which thus yielded 55 
observations to work with. Since the main purpose of this article was comparing linear and non-linear modelling methods, the $80 \mathrm{~s}$ was not included in the sample period because it was characterized by sanctions, fixed exchange rates and different political regimes, which have other challenges such as structural breaks.

All the equations in the linear model were found to be non-linear and therefore the data was transformed logarithmically in order to induce linearity. The model was simultaneously solved in-sample as well as out-of-sample, yielding mixed results.

\subsection{Non-linear model}

A smooth transition autoregressive (STAR) model was used to represent the non-linear specification part of the combination model. The STAR methodology was decided upon since this method best suits the quarterly macroeconomic model. Smooth transition models are an attractive method to use with macroeconomic time series because the data are often the results of decisions made by a large number of economic agents. According to Teräsvirta (1994) it is more realistic to assume that the process whereby agents change their behaviour occurs smoothly rather than discretely, which is accommodated for by the STAR methodology.

Smooth transition models can be tracked back to Bacon and Watts (1971) and have been applied with some success in terms of forecasting to different time series by Teräsvirta and Anderson (1992), Kilian and Taylor (2003) and Marcellino (2005). Mixed and more negative results were obtained from Sarantis (1999) and Boero and Marrocu (2002).

Since the STAR methodology is univariate in nature, it was decided not to transform the complete model to a non-linear one so that all interaction between variables will not be lost in the non-linear model. The non-linear specification will thus only be applied to eight linear problem-identified equations while the other equations will keep their linearinduced specification. The model was again solved simultaneously in-sample as well as out-of-sample.

The methodology followed for the STAR model can be summarized in Figure 1 (on the following page). The non-linear process was started with the specification of the best linear model for the data (an autoregressive model). A tentative threshold autoregressive model was then built, and this was used to determine the delay parameter and the threshold. The STAR model was constructed with the incorporation of the delay parameter and the threshold. A Wald test was performed to determine whether the data is best modelled as an LSTAR or ESTAR process. The combination model's performance was compared to that of the pure linear model in-sample as well as out-of-sample.

\section{LINEAR SPECIFICATIONS}

For the purpose of this article only two variables and their forecasts will be discussed, namely: Claims by the private sector on the monetary sector; Export prices without gold. 
FIGURE 1: The non-linear approach to econometric model building

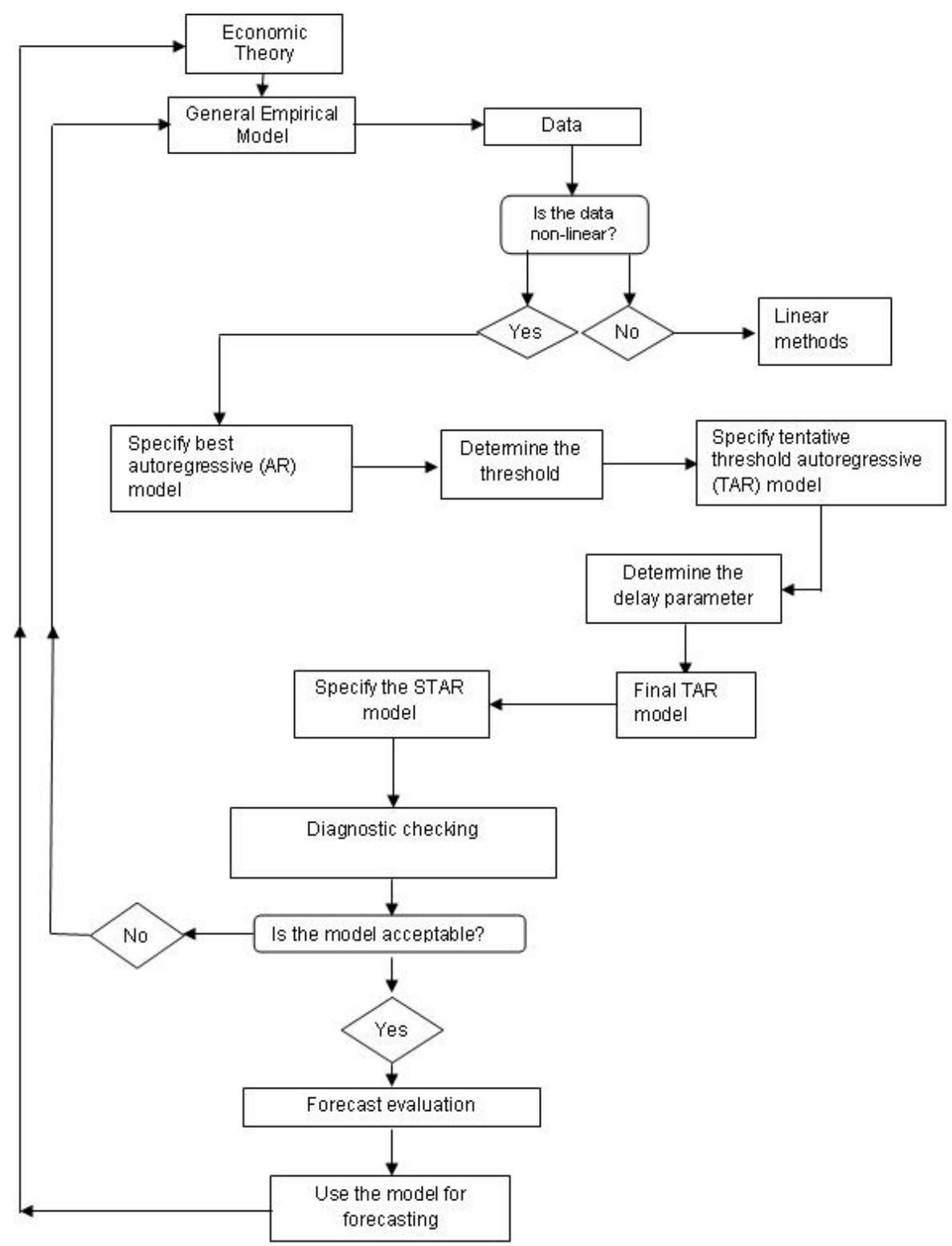

Source: Adapted from Botha (2004)

\subsection{Claims by the private sector on the monetary sector [CREDIT]}

CREDIT $=f(3 M B A R$, WAGER)

where CREDIT Claims by the private sector on the monetary sector at current prices 
3MBAR 3-month bankers acceptance rate

WAGER Wage rate in the non-agricultural sector at current prices

The demand for money was represented by total credit that is extended to the domestic private sector. If the price of credit (interest rates, 3MBAR) increased, it decreased the demand for credit (CREDIT), because opportunity cost subsequently increased.

As soon as individuals' income increased significantly, individuals' living standards are adjusted accordingly and the use of credit is increased as well. A definite positive relationship was thus expected between CREDIT and WAGER.

The equation was found non-linear with the use of the Wald-test and therefore the data was transformed logarithmically in order to induce linearity. The equation was also found to be cointegrated (after unit roots were detected) and the regression results were as follows:

TABLE 1: Regression results for CREDIT

\begin{tabular}{lccc}
\hline \multicolumn{4}{c}{ Dependent Variable: LOG(CREDIT) } \\
\hline \multicolumn{1}{c}{ Variable } & Coefficient & Std. Error & t-Statistic \\
C & 0.017950 & 0.793944 & 0.022608 \\
LOG(WAGER) & 1.255449 & 0.049324 & 25.45322 \\
PDLO1 & 0.012728 & 0.013697 & 0.929278 \\
PDLO2 & -0.000975 & 0.001925 & -0.506691 \\
PDLO3 & -0.001562 & 0.000638 & -2.450046 \\
R-squared & 0.982214 & Mean dependent var & 12.83787 \\
Adjusted R-squared & 0.980896 & S.D. dependent var & 0.538111 \\
S.E. of regression & 0.074375 & Akaike info criterion & -2.278448 \\
Sum squared resid & 0.298711 & Schwarz criterion & -2.102385 \\
Log likelihood & 72.21420 & F-statistic & 745.5207 \\
Durbin-Watson stat & 1.118330 & Prob(F-statistic) & 0.000000 \\
\hline
\end{tabular}

Source: Eviews results

The sign and magnitudes of the coefficients all made economic sense. A PDL $(15,2)$ was fitted to the regression and all the variables were found to be statistically significant. The adjusted $R^{2}$ and $F$-statistic both indicate a good model. Multicollinearity and heteroskedasticity was found absent in the model and autocorrelation was corrected using the Newey-West method.

After the function was simulated ex post, tests were done in order to test the in-sample as well as out-of-sample forecasting power of the model. The RMSE percentage was relatively big $(14.03 \%)$, indicating that the out-of-sample forecasting ability of the model was not good. Theil's inequality coefficient was close to zero and the biggest component of the error 
was due to the non-systematic disturbance which was unsolvable for the modeller. The insample forecasting ability of the model compared better to the out-of-sample forecasting ability.

\title{
3.2 Export prices without gold [EXPORTP]
}

\author{
EXPORTP $=f($ WCOMMP, USAEXC) \\ where $\quad$ EXPORTP $=$ Export prices without gold \\ WCOMMP = World commodity prices \\ USAEXC = Exchange rate: USA
}

WCOMMP was divided by WCOMMP lagged by 4 periods in order to represent the growth rate in the world commodity prices. If prices of primary goods (represented by WCOMMP) like platinum and palladium increased, the prices of export goods also increased. A positive relationship was therefore expected between EXPORTP and WCOMMP.

If the Rand/\$ exchange rate (USAEXC) depreciated (increased) export prices also increased due to the fact foreigners now have to pay more for their imports. A positive relationship was thus again expected between EXPORTP and USAEXC.

The equation was found non-linear with the use of the Wald-test and therefore the data was transformed logarithmically in order to induce linearity. The equation was also found to be cointegrated (after unit roots were detected) and the regression results were as follows:

TABLE 2: Regression results for EXPORTP

\begin{tabular}{lccc}
\hline \multicolumn{4}{c}{ Dependent Variable: LOG(EXPORTP) } \\
\hline \multicolumn{1}{c}{ Variable } & Coefficient & Std. Error & t-Statistic \\
C & -5.452200 & 0.219725 & -24.81375 \\
LOG(USAEXC) & 0.842461 & 0.037136 & 22.68596 \\
LOG(WCOMMP/WCOMMP(-4)) & 0.412287 & 0.173270 & 2.379454 \\
R-squared & 0.955755 & $\begin{array}{l}\text { Mean dependent } \\
\text { var }\end{array}$ & -0.251203 \\
Adjusted R-squared & 0.954175 & $\begin{array}{l}\text { S.D. dependent } \\
\text { var }\end{array}$ & 0.387794 \\
S.E. of regression & 0.083014 & $\begin{array}{l}\text { Akaike info } \\
\text { criterion }\end{array}$ & -2.090100 \\
Sum squared resid & 0.385916 & Schwarz criterion & -1.984463 \\
Log likelihood & 64.65795 & F-statistic & 604.8416 \\
Durbin-Watson stat & 0.354304 & Prob(F-statistic) & 0.000000 \\
\hline
\end{tabular}

Source: Eviews results 
The sign and magnitudes of the coefficients all made economic sense. The adjusted $R^{2}$ and F-statistic both indicated a good model. It was found that multicollinearity was not present in the data. Heteroskedasticity and autocorrelation were corrected with the Newey-West method.

After the function was simulated ex post, tests were done in order to test the in-sample as well as out-of-sample forecasting power of the model. The RMSE percentage was quite big (17.97\%), which indicated that the out-of-sample forecasting ability of this specific equation was not good at all. Theil's inequality coefficient was relatively close to zero and the biggest component of the error was due to the non-systematic disturbance which was unsolvable for the modeller. The in-sample forecasting ability of the model was satisfactory.

\section{NON-LINEAR SPECIFICATIONS}

\subsection{Claims by private sector on the monetary sector [CREDIT]}

The data was transformed to fourth-quarter differences seeing that it exhibited seasonality. The logarithmic form of the data was used because the equation still needs to be linear in the parameters.

\subsubsection{Autoregressive model for CREDIT}

A simple autoregressive model was fitted to the CREDIT data. The appropriate lag structure was determined by using the Schwarz information criterion (SIC). The most significant lags were $1,4,5$ and 8 . The best linear model that fitted the data is presented in Table 3. Autocorrelation and heteroskedasticity were not present in the model. The non-linear model was based on this autoregressive model.

\subsubsection{Identifying the threshold of the data for CREDIT}

The estimated autoregressive model was used as a basis for identifying the threshold for the data. To determine the band of threshold the $15 \%$ percentile and the $85 \%$ percentile were calculated and all possible thresholds between these two values were tested.

The threshold autoregressive (TAR) model for each value within the $70 \%$ threshold band was estimated. The one with the lowest RSS and SIC value was chosen as the applicable threshold. This turned out to be 0.14 . It is assumed that there was only one threshold because there was not a significant difference between the various RSS values for the threshold values within the band.

\subsubsection{Determining the delay parameter for CREDIT}

The procedure suggested by Enders (2004) to determine the delay parameter was used. After running the TAR model with various delay possibilities, $Y_{t-2}$ was the most significant with the lowest Schwarz value. 
TABLE 3: Results of the Autoregressive Model for CREDIT

\begin{tabular}{lccc}
\hline \multicolumn{4}{c}{ Dependent Variable: DLOG(CREDIT,0,4) } \\
\hline \multicolumn{1}{c}{ Variable } & Coefficient & Std. Error & t-Statistic \\
$\mathrm{C}$ & 0.125071 & 0.007625 & 16.40302 \\
$\mathrm{AR}(1)$ & 0.744262 & 0.091117 & 8.168189 \\
$\mathrm{AR}(4)$ & -0.517486 & 0.149063 & -3.471590 \\
$\mathrm{AR}(5)$ & 0.723399 & 0.157107 & 4.604486 \\
$\mathrm{AR}(8)$ & -0.357971 & 0.107082 & -3.342947 \\
$R$-squared & 0.702339 & Mean dependent var & 0.122258 \\
Adjusted R-squared & 0.673991 & S.D. dependent var & 0.037015 \\
S.E. of regression & 0.021134 & Akaike info criterion & -4.775534 \\
Durbin-Watson stat & 1.701816 & Prob(F-statistic) & 0.000000 \\
\hline
\end{tabular}

Source: $\varepsilon$ views results

\subsubsection{Smooth transition autoregressive model for CREDIT}

\subsubsection{The LSTAR model of CREDIT}

The basic TAR model, the threshold and the determined delay parameter were all used to build the LSTAR model. The logistic function was added to the model to structure the LSTAR model. The following LSTAR model proved to be the best:

TABLE 4: Results of the LSTAR Model for CREDIT

\begin{tabular}{|c|c|c|c|}
\hline \multicolumn{4}{|c|}{ Dependent Variable: DLOG $(C R E D I T, 0,4)$} \\
\hline & Coefficient & Std. Error & $t$-Statistic \\
\hline$\alpha_{0}$ & 0.236489 & 0.029841 & 7.925037 \\
\hline$\alpha_{1}$ & -0.477185 & 0.145157 & -3.287369 \\
\hline$\alpha_{2}$ & -0.391615 & 0.103169 & -3.795869 \\
\hline$\beta_{0}$ & -0.433522 & 0.085821 & -5.051486 \\
\hline$\beta_{1}$ & 1.774792 & 0.259257 & 6.845685 \\
\hline$\beta_{2}$ & 1.525355 & 0.295814 & 5.156469 \\
\hline$\theta_{0}$ & -11.49342 & 4.939244 & -2.326960 \\
\hline$R$-squared & 0.740000 & Mean dependent var & 0.122258 \\
\hline Adjusted R-squared & 0.701000 & S.D. dependent var & 0.037015 \\
\hline
\end{tabular}




$\begin{array}{llll}\text { S.E. of regression } & 0.020240 & \text { Akaike info criterion } & -4.825700 \\ \text { Sum squared resid } & 0.016386 & \text { Schwarz criterion } & -4.550146 \\ \text { Loglikelihood } & 120.4039 & \text { Durbin-Watson stat } & 1.722873\end{array}$

Source: Eviews results

The best model was chosen according to the lowest SIC value. The coefficients were all significant on the $95 \%$ level. Once the STAR model was specified, tests were conducted in order to see whether the series was best modelled as an LSTAR or an ESTAR process. In order to do this the coefficients to the third power of an auxiliary regression were restricted using the Wald test. The Wald test confirmed that the model has an ESTAR form.

\subsubsection{The ESTAR model for CREDIT}

The basic STAR model was again used; however, this time the logistic function was replaced with the exponential function. The ESTAR results are presented in Table 5.

TABLE 5: Results of the ESTAR model for CREDIT

\begin{tabular}{lccc}
\hline \multicolumn{4}{c}{ Dependent Variable: DLOG(CREDIT,0,4) } \\
\hline$\alpha_{0}$ & Coefficient & Std. Error & t-Statistic \\
$\alpha_{1}$ & 0.255498 & 0.035702 & 7.156419 \\
$\alpha_{2}$ & -0.524950 & 0.151787 & -3.458472 \\
$\beta_{0}$ & -0.346817 & 0.112305 & -3.088184 \\
$\beta_{1}$ & -0.206211 & 0.034064 & -6.053567 \\
$\beta_{2}$ & 0.741612 & 0.095085 & 7.799426 \\
$\theta_{0}$ & 0.735603 & 0.160355 & 4.587347 \\
$R$-squared & -116044.2 & 298235.5 & -0.389103 \\
Adjusted R-squared & 0.706748 & Mean dependent var & 0.122258 \\
S.E. of regression & 0.021495 & Akaike info criterion & -4.705351 \\
Sum squared resid & 0.018482 & Schwarz criterion & -4.429797 \\
Log likelihood & 117.5758 & Durbin-Watson stat & 1.709668 \\
\hline Source:Eviews & &
\end{tabular}

Source: Eviews results

The best ESTAR model was determined by using the lowest SIC value. With the exception of one of the constants, all of the coefficients were significant on a $95 \%$ level of significance. Diagnostically, the Jarque-Bera statistic indicated that the residuals were not normally distributed, but the positive skewness and excess kurtosis can be attributed to the residuals corresponding to external shocks. The STAR model therefore explained movements in 
CREDIT.

The forecast evaluation for CREDIT turned out to be very satisfactory. The RMSE percentage was extremely small $(0.15 \%)$, indicating the good out-of-sample forecasting ability of the model. Theil's inequality coefficient was relatively close to zero and the biggest component of the error was due to the non-systematic disturbance which was unsolvable for the modeller. The in-sample forecasting ability of the model was thus very good as well.

\subsection{Export prices without gold [EXPORTP]}

The data was transformed to fourth-quarter differences seeing that it exhibited seasonality. It was also differenced once in order to make it stationary. The logarithmic form of the data was used, as the equation still needs to be linear in the parameters.

\subsubsection{Autoregressive model for EXPORTP}

A simple autoregressive model was fitted to the EXPORTP data. The appropriate lag structure was determined by way of the Schwarz information criterion (SIC). The most significant lags were 2 and 4 . The best linear model that fitted the data is presented in Table 6. Autocorrelation and heteroskedasticity were not present in the model. The nonlinear model was based on this autoregressive model.

TABLE 6: Results of the Autoregressive Model for EXPORTP

\begin{tabular}{lccc}
\hline \multicolumn{4}{c}{ Dependent Variable: DLOG(EXPORTP, 1,4) } \\
\hline \multicolumn{1}{c}{ Variable } & Coefficient & Std. Error & t-Statistic \\
C & -0.002453 & 0.005420 & -0.452600 \\
AR(2) & 0.260099 & 0.099940 & 2.602565 \\
AR(4) & -0.695431 & 0.100906 & -6.891892 \\
R-squared & 0.514218 & Mean dependent var & -0.002205 \\
Adjusted R-squared & 0.493547 & S.D. dependent var & 0.077262 \\
S.E. of regression & 0.054984 & Akaike info criterion & -2.905418 \\
Sum squared resid & 0.142093 & Schwarz criterion & -2.790697 \\
Log likelihood & 75.63546 & F-statistic & 24.87565 \\
Durbin-Watson stat & 2.292561 & Prob(F-statistic) & 0.000000 \\
\hline Source: Eviews results & & &
\end{tabular}

Source: Eviews results

\subsubsection{Identifying the threshold of the data for EXPORTP}

The estimated autoregressive model was used as a basis for identifying the threshold for the data. To determine the band of threshold the $15 \%$ percentile and the $85 \%$ percentile were calculated and all possible thresholds between these two values were tested. 
The TAR model for each value within the $70 \%$ threshold band was estimated. The one with the lowest residual sum of squares (RSS) and the Schwarz information criteria (SIC) value was chosen as the applicable threshold. This turned out to be 0.07 . It was assumed that there was only one threshold because there is not a significant difference between the various RSS values for the threshold values within the band.

\subsubsection{Determining the delay parameter for EXPORTP}

The procedure suggested by Enders (2004) to determine the delay parameter was used. After running the TAR model with various delay possibilities, $Y_{t-5}$ was the most significant with the lowest Schwarz value.

\subsubsection{Smooth transition autoregressive model for EXPORTP}

\subsubsection{The LSTAR model for EXPORTP}

The basic TAR model, the threshold and the determined delay parameter were all used to specify the LSTAR model. The logistic function was added to the model to structure the LSTAR model. The following LSTAR model proved to be the best:

\section{TABLE 7: Results of the LSTAR Model for EXPORTP}

\begin{tabular}{lccc}
\hline \multicolumn{4}{c}{ Dependent Variable: DLOG $($ EXPORTP, 1,4) } \\
\hline$\alpha_{0}$ & Coefficient & Std. Error & t-Statistic \\
$\alpha_{1}$ & -0.066543 & 0.012997 & -0.503369 \\
$\beta_{0}$ & -0.686450 & 0.100441 & -6.834388 \\
$\beta_{1}$ & 0.008508 & 0.039132 & 0.217406 \\
$\theta_{0}$ & 1.111713 & 0.300147 & 3.703899 \\
$R$-squared & -16.89883 & 7.695388 & -2.195969 \\
Adjusted R-squared & 0.606082 & Mean dependent var & 0.000141 \\
S.E. of regression & 0.570271 & S.D. dependent var & 0.076243 \\
Sum squared resid & 0.049980 & Akaike info criterion & -3.057933 \\
og likelihood & 0.109912 & Schwarz criterion & -2.864890 \\
\hline Source:Eviews & 79.91935 & Durbin-Watson stat & 2.205452 \\
\hline
\end{tabular}

Source: Eviews results

The best model was chosen according to the lowest SIC value. The coefficients were all significant on the $95 \%$ level, except for some of the constants. Once the STAR model was specified, tests were conducted to see whether the series was best modelled as an LSTAR or an ESTAR process. In order to do this the coefficients to the third power of an auxiliary 
regression were restricted using the Wald test. The Wald test confirmed that the model has an ESTAR form.

4.2.4.2 The ESTAR model for EXPORTP

The ESTAR model was specified by replacing the logistic function with the exponential function. The ESTAR results are presented in Table 8.

TABLE 8: Results of the ESTAR model for EXPORTP

\begin{tabular}{lccc}
\hline \multicolumn{4}{c}{ Dependent Variable: DLOG(EXPORTP, 1,4) } \\
\hline$\alpha_{0}$ & Coefficient & Std. Error & t-Statistic \\
$\alpha_{1}$ & 0.022720 & 0.042235 & 0.537941 \\
$\beta_{0}$ & 0.329776 & 0.098566 & 3.345740 \\
$\beta_{1}$ & -0.023320 & 0.043017 & -0.542107 \\
$\theta_{0}$ & -0.704153 & 0.097289 & -7.237734 \\
$R$-squared & -8342.618 & 23922.55 & -0.348734 \\
Adjusted R-squared & 0.568461 & Mean dependent var & 0.000141 \\
S.E. of regression & 0.529230 & S.D. dependent var & 0.076243 \\
Sum squared resid & 0.052312 & Akaike info criterion & -2.966718 \\
Log likelihood & 0.120409 & Schwarz criterion & -2.773676 \\
\hline Source:Eviewsresults & 77.68460 & Durbin-Watson stat & 2.212075 \\
\hline
\end{tabular}

Source: Eviews results

\section{COMPARISON OF FORECASTS}

\subsection{Comparison of forecasts of CREDIT}

The out-of-sample forecasts are graphically represented in Figure 2. Visually the nonlinear model compared favourably to the actual data out-of-sample. It can be seen that the non-linear model fits the data much better than the linear model. 
FIGURE 2: Actual data vs. linear model vs. non-linear model (CREDIT)

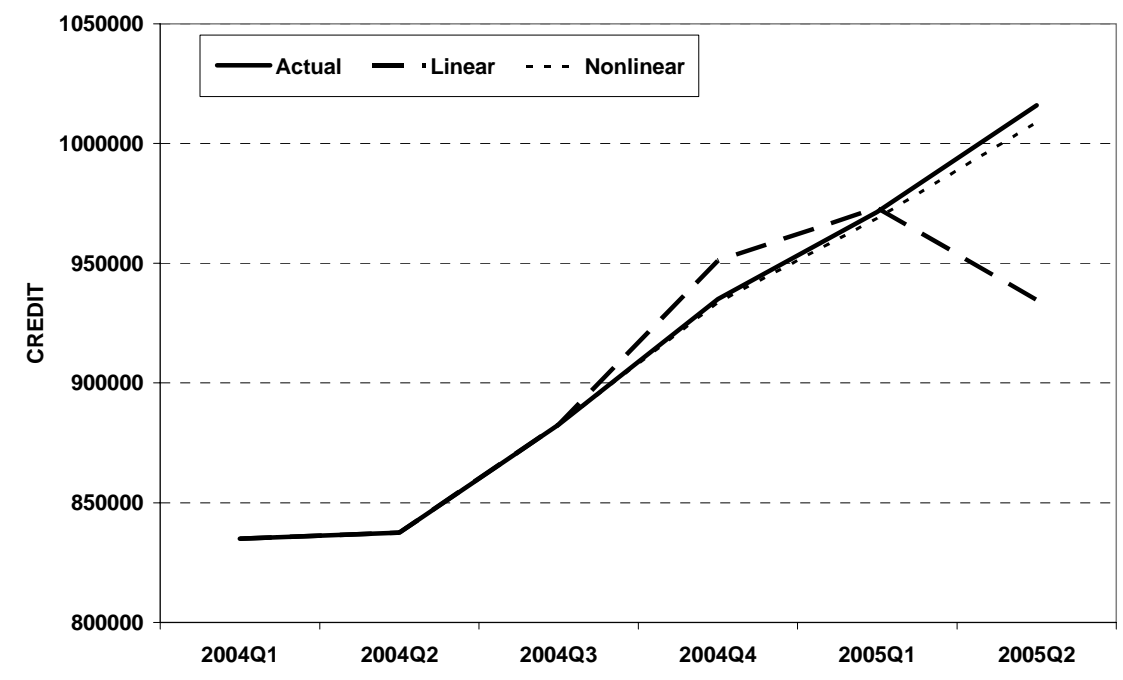

Source: Results

The forecast evaluation statistics comparison in Table 9 indicates that the non-linear combination model outperformed the pure linear model out-of-sample but not necessarily in-sample.

TABLE 9: Comparison of forecast evaluation CREDIT

\begin{tabular}{lcc}
\hline \multicolumn{1}{c}{ Forecast evaluation } & Linear & Non-linear \\
\hline RMSE & 48595.29 & 0.019830 \\
RMSE (\%) & 14.03022 & 0.154465 \\
Theil's inequality coefficient & 0.034539 & 0.078164 \\
Bias proportion & 0.003951 & 0.000000 \\
Variance proportion & 0.040927 & 0.086546 \\
Covariance proportion & 0.955122 & 0.913454 \\
\hline
\end{tabular}

Source: Own calculations

\subsection{Comparison of forecasts for EXPORTP}

The out-of-sample forecasts can be graphically represented by Figure 3. Visually the nonlinear model compares favourably to the actual data out-of-sample. This is a definite improvement on the linear specification. 
FIGURE 3: Actual data vs. linear model vs. non-linear model (EXPORTP)

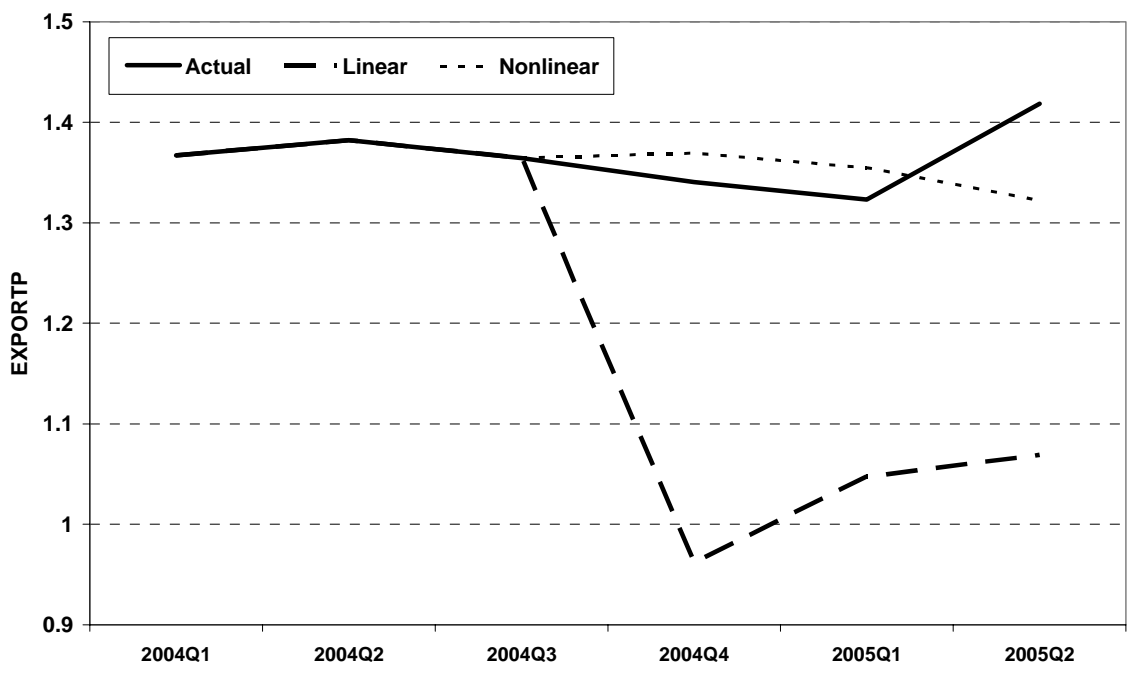

Source: Results

The forecast evaluation statistics comparison in Table 10 indicates that the non-linear combination model outperformed the pure linear model out-of-sample but not necessarily in-sample.

TABLE 10: Comparison of forecast evaluation EXPORTP

\begin{tabular}{lcc}
\hline \multicolumn{1}{c}{ Forecast evaluation } & Linear & Non-linear \\
\hline RMSE & 0.120682 & 0.049572 \\
RMSE (\%) & 17.97444 & 5.909509 \\
Theil's inequality coefficient & 0.049958 & 0.374532 \\
Bias proportion & 0.000914 & 0.000000 \\
Variance proportion & 0.005450 & 0.140275 \\
Covariance proportion & 0.993636 & 0.859725
\end{tabular}

Source: Own calculations

In both models discussed in this article, the RMSE \% was significantly improved with the incorporation of non-linear specifications in the macroeconomic model. The RMSE \% improved from $14 \%$ to $0.15 \%$ for CREDIT and from $18 \%$ to $6 \%$ for EXPORTP, indicating that a combination of linear and non-linear specifications in a macroeconomic model simulation could improve the forecasting performance of such a model. 


\section{CONCLUSION}

This article considered the forecasting accuracy of a pure linear as well as a combination of linear and non-linear specifications of a macroeconomic model of the South African economy. The linear specification was represented by a multivariate ordinary least squares model. The non-linear specification was symbolized by combining multivariate ordinary least square specifications as well as smooth transition autoregressive (STAR) specifications (thus univariate in nature).

The results in the preceding section suggest that the combination non-linear specification outperforms the linear specification out-of-sample but not in-sample. These results correspond with Teräsvirta et al (2005), which state that STAR models are somewhat more accurate than forecasts from pure linear models.

"Supposing that the world is inherently non-linear, then as computational capabilities increase, more complex models become amenable to analysis, allowing the possibility that future generations of models will significantly outperform linear models, especially if such models become truly multivariate" (Clements, Franses \& Swanson, 2003).

\section{REFERENCES}

Bacon, D.W. \& Watts, D.0. (1971). Estimating the transition between two intersecting straight lines. Biometrika, 58, pp. 525-534.

Boero, G., \& Marrocu, \&. (2002). The performance of non-linear exchange rate models: A forecast comparison. Journal of Forecasting, 21, pp. 513-542.

Botha, I. (2004). Modelling the Business Cycle of South Africa: Linear vs. Nonlinear methods. Johannesburg: Randse Afrikaanse Universiteit (DCom Thesis).

Clements, M.P., Franses, P.H. \& Swanson, N.R. (2003). Forecasting economic and financial time series with non-linear models. Departmental Working papers 200309, Rutgers University, Department of Economics.

Enders, W. (2004). Applied Econometric Time Series. John Wiley \& Sons: USA.

Erjavec, N. (2003). Applied Macroeconometrics in Transition Economy: Croatian Experience. The Centre for the Study of Global Governance, Discussion Paper 25. Available from: http://www.Ise.ac.uk/Depts/global/Erjavecpaper.htm (Accessed on 8 April 2006).

Greene, W.H. (2003). Econometric Analysis. Pearson Education: New Jersey.

Jerome, A. (2004). A Survey of Macroeconomic Models for Policy Analysis and Forecasting in South Africa. Prepared for presentation at the $9^{\text {th }}$ Annual Econometrics Modelling for Africa, University of Cape Town, June 30-July 2, 2004.

Kilian, L., \& Taylor, M. (2003). Why is it so difficult to beat the random walk forecast of exchange rates? Journal of International Economics, 60, pp. 85-107.

Marcellino, M. (2005). Instability and non-linearity in the EMU. (In: Milas, C., Rothman, P. \& Van Dijk , D (Eds.), Nonlinear Time Series Analysis of Business Cycles. Amsterdam: Elsevier). 
Sarantis, N. (1999). Modelling non-linearities in real effective exchange rates. Journal of Internationa/ Money and Finance, 18, pp. 27-45.

Teräsvirta, T. (1994). Specification, Estimation, and Evaluation of Smooth Transition Autoregressive Models. Journal of the American Statistical Association, 89(425), pp. 208218.

Teräsvirta, T \& Anderson, H.M. (1992). Characterizing Nonlinearities in Business Cycles using Smooth Transition Autoregressive Models. Journal of Applied Econometrics, 7, pp. S119S136.

Teräsvirta, T, Van Dijk, D. \& Medeiros, M.C. (2004). Linear models, smooth transition autoregression, and neural networks for forecasting macroeconomic time series: A reexamination. Working paper series in Economics and Finance number 561: Stockholm School of Economics. 